\title{
Association of adrenal insufficiency with patient-oriented health-care outcomes in adult medical inpatients
}

\author{
Fahim Ebrahimi 1,*, Andrea Widmer, ${ }^{1, *}$, Ulrich Wagner ${ }^{2,6}$, Beat Mueller ${ }^{3,4,5}$, Philipp Schuetz ${ }^{3,4,5}$, \\ Mirjam Christ-Crain ${ }^{1,5}$ and Alexander Kutz ${ }^{1,3}$
}

${ }^{1}$ Division of Endocrinology, Diabetes, and Metabolism, University Hospital Basel, Basel, Switzerland, ${ }^{2}$ Division of Health and Social Affairs, Section Health, Swiss Federal Office for Statistics, Neuchâtel, Switzerland, ${ }^{3}$ Division of General Internal and Emergency Medicine, University Department of Medicine, Kantonsspital Aarau, Aarau, Switzerland, ${ }^{4}$ Division of Endocrinology, Diabetes, and Metabolism, University Department of Medicine, Kantonsspital Aarau, Aarau, Switzerland, ${ }^{5}$ Faculty of Medicine, University of Basel, Basel, Switzerland, and ${ }^{6}$ Foundation National Institute for Cancer Epidemiology and Registration (NICER), University of Zurich, Zurich, Switzerland

*(F Ebrahimi and A Widmer contributed equally to this work)

Correspondence should be addressed to A Kutz

Email

kutz.alexander@gmail.com

\section{Abstract}

Objective: Adrenal insufficiency in the outpatient setting is associated with excess morbidity, mortality, and impaired quality of life. Evidence on its health-care burden in medical inpatients is scarce. The aim of this study was to assess the health-care burden of primary adrenal insufficiency (PAI) and secondary adrenal insufficiency (SAI) among hospitalized inpatients.

Design and methods: In this nationwide cohort study, adult medical patients with either PAI or SAI hospitalized between 2011 and 2015 were compared with propensity-matched (1:1) medical controls, respectively. The primary outcome was 30-day all-cause in-hospital mortality. Main secondary outcomes included ICU admission rate, length-of-hospital stay, 30-day and 1-year all-cause readmission rates.

Results: In total, 594 hospitalized cases with PAI and 4880 cases with SAI were included. Compared with matched controls, in-hospital mortality was not increased among PAI or SAI patients, respectively. Patients with adrenal insufficiency were more likely to be admitted to ICU (PAI: OR $1.9(95 \% \mathrm{Cl}, 1.27$ to 2.72 ) and SAl: OR 1.5 (95\% Cl, 1.35 to 1.75)). Length of hospital stay was prolonged by 1.0 days in PAl patients ( 8.9 vs 7.9 days ( $95 \% \mathrm{Cl}, 0.06$ to 1.93$)$ ), and by 3.3 days in SAl patients ( 12.1 vs 8.8 days $(95 \% \mathrm{Cl}, 2.82$ to 3.71$)$ ), when compared with matched controls. Patients with SAI were found to have higher 30 -day and 1 -year readmission rates (14.1 vs $12.1 \%$ and 50.0 vs $40.7 \% ; P<0.001)$ than matched controls.

Conclusions: While no difference in in-hospital mortality was found, adrenal insufficiency was associated with prolonged length of hospital stay, and substantially higher rates of ICU admission and hospital readmission.

\section{Introduction}

Adrenal insufficiency is a potentially life-threatening disease and classified into primary adrenal insufficiency (PAI) and secondary adrenal insufficiency (SAI), respectively. In PAI steroid hormone production in the adrenal cortex is reduced $(1,2)$, whereas in patients with SAI, the disorder is at the level of the hypothalamic- pituitary-adrenal (HPA) axis (1, 3, 4, 5). If adrenal insufficiency is not recognized and substitution of in particular glucocorticoid hormones is not being initiated, the majority of patients will die within 2 years after diagnosis (6). While glucocorticoids help achieve sufficient quality of life (7), acute management of adrenal

\section{This work is licensed under a Creative Commons} Attribution 4.0 International License. 
insufficiency in emergency situations especially among hospitalized patients remains a challenge in acute care institutions $(8,9)$.

Both, patients with PAI and patients with SAI, are known to have higher risks for metabolic and psychiatric comorbidities and their risk for hospital admission is elevated as compared to the general population (10).

Patients with SAI have an excess mortality, especially from vascular and respiratory disease (11). Similarly, the risk for death is more than two-fold increased among patients with PAI when compared with the general population (12). Excess mortality was highest when the patients were diagnosed at young age (13). Underlying reasons for the mortality gap were identified to being cardiovascular, malignant or infectious diseases $(12,14)$. Whether this association between PAI and infections is related to PAI itself or due to unphysiological adrenal replacement therapy is debated (14).

As most of the studies were done in the outpatient setting, evidence on health-care burden of either PAI or SAI among medical inpatients remains scarce. Herein, we investigated in a propensity-matched in-hospital population-based cohort the impact of adrenal insufficiency on patient-centered health care outcomes (i.e. 30-day all-cause in-hospital mortality, intensive care unit (ICU) admission, length of ICU stay, intubation rate, length of intubation, length of hospital stay (LOS), and all-cause readmission rates).

\section{Subjects and methods}

\section{Participants, data sources, and study variables}

In this nationwide cohort study, data were provided by the Swiss Federal Office for Statistics (Bundesamt für Statistik, Neuchâtel, Switzerland). In this database, the patient information is fully anonymized. No written informed consent was given to the patients who were unidentifiable due to pseudo-anonymization. The database includes all Swiss inpatient discharge records from acute care, general, and specialty hospitals, excluding hospital units of postacute care institutions, regardless of payer, and thus, creates a near $100 \%$ sample of inpatient discharges in Switzerland between 2011 and 2015. Each patient in this database was identified uniquely so that re-hospitalizations could be tracked. A single patient may have more than one index admission in the study period. According to the SwissDRG definition, all admissions after 18 days from discharge or admissions into another hospital were defined as new case in the nationwide hospital claims data (15). For the endpoint of all-cause readmission rate, every re-hospitalization - either within 30 days or within 1 year, respectively - after discharge were counted as hospital readmission. Solely emergency admissions to hospital were included, whereas planned hospitalizations were excluded from the analysis. In patients who were transferred between acute care hospitals, the hospital stays were combined into a single episode of care and the patient outcome was attributed to the first hospitalization. The database included information such as patient's residency, hospital teaching level, year and month of hospitalization, LOS as well as age at admission and admission diagnosis. Medical diagnoses were coded using the International Classification of Disease, version 10, German Modification (ICD-10 GM) codes (http://www. who.int/classifications/icd/en/). AIl hospitalizations were identified by applying (ICD-10-GM) code of E27.1 for PAI and E27.3 and E89.6 for SAI to primary or secondary discharge diagnoses, respectively. Patients without clear diagnosis of either PAI or SAI were not included in the analysis. Patients with tertiary adrenal insufficiency due to long-term administration of high doses of glucocorticoids were pooled with SAI patients. Nonmedical, psychiatric, and nonadult $(<18$ years of age) patients were excluded from the analysis.

The Institutional Review Board of Northwestern Switzerland approved this study and waived informed patient consent owing to the use of deidentified data. This study followed the Strengthening The Reporting of OBservational studies in Epidemiology (STROBE) reporting guideline (16).

\section{Outcomes}

The primary outcome was 30-day all-cause in-hospital mortality. Secondary outcomes comprised ICU admission rate, length of ICU stay, intubation rate, length of intubation time, LOS - defined as days spent in the hospital during the hospitalization, as well as 30-day and 1-year all-cause readmission rates.

\section{Statistical analysis}

Hospitalized cases meeting inclusion and exclusion criteria within each study cohort (PAI and SAI) were 1:1 propensity score matched to a general medical inpatient control group (matched control) using a nearest-neighbor matching algorithm. For optimal matching HosmerLemeshow goodness of fit and concordance c-statistics were 
utilized to assess the fitness of the models. Furthermore, we used a threshold of $10 \%$ in the standardized difference as a meaningful imbalance between the two groups (17). Cases were matched based on age, sex, race/ethnicity, year of hospitalization, hospital teaching level, Charlson Comorbidity Index (CCI), admission diagnosis, and important comorbidities. Summary statistics were calculated for patient demographics and major comorbid conditions for each study cohort. Estimates of the effect size and corresponding 95\% confidence intervals (CI) were determined using linear, logistica or Cox proportional hazards regression as appropriate. All $P$ values are twosided and have not been adjusted for multiple testing. Kaplan-Meier curves were used to illustrate differences in time to in-hospital death, time to discharge and time to readmission. All CIs are at the 95\% level. Statistical analyses were performed using STATA, version 15.1 (StataCorp LLC).

\section{Results}

\section{Patient characteristics}

Between January 2011 through December 2015, we identified 6922291 hospitalizations of whom 5474 fulfilled eligibility criteria for matching. Of those, 594 hospitalized cases with PAI and 4880 cases with SAI were matched 1:1 with medical controls (Fig. 1). As designed, baseline characteristics were similar between both matched adrenal insufficiency cohorts (Table 1) without any significant differences. Among all study cohorts, median age was around 65 years and slightly more patients were female. Most key comorbid conditions were higher across patients with SAI when compared with PAI patients with higher rates of hypertension (47 vs $31 \%$ ), renal insufficiency (31 vs 25\%), chronic obstructive pulmonary disease (27 vs $12 \%$ ), as well as cancer (22 vs $12 \%$ ). Accordingly, patients with SAI had higher comorbidity indices shown by the CCI (2.4 vs 1.6 points). Causes of initial hospital admission were well matched among cases with PAI as well as SAI and their respective controls (Supplementary Fig. 1, see section on supplementary data given at the end of this article). Among cases with PAI, endocrine conditions were the predominant cause $(25.9 \%)$ and infectious diseases the second prevalent cause (14.5\%) of hospital admission. In contrast, among patients with SAI, respiratory conditions were the leading cause of hospital admission (21.4\%), followed by oncologic/hematologic diseases (14.5\%) (Supplementary Fig. 1).

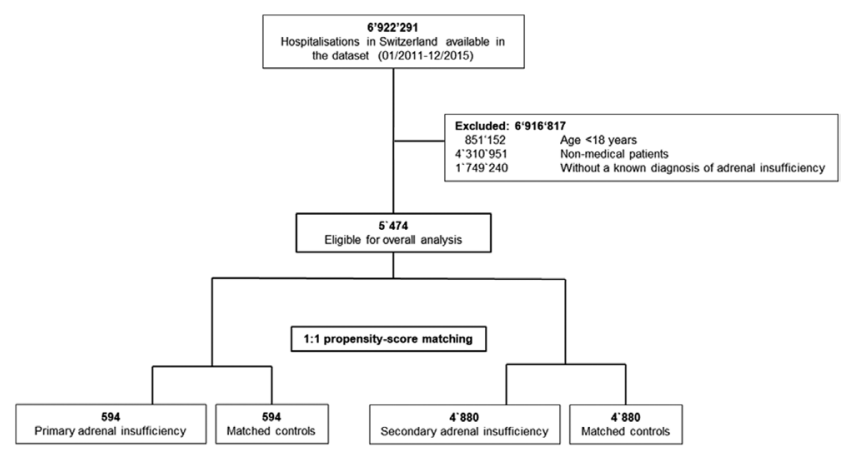

Figure 1

Flow chart of included hospitalized cases.

\section{Thirty-day all-cause in-hospital mortality}

In-hospital mortality rates within 30 days were overall comparably low ranging from $3.9 \%$ (odds ratio (OR) $1.05,95 \%$ CI 0.58 to 1.90 ) in the matched PAI cohorts to $4.9 \%$ (OR $1.12,95 \% \mathrm{CI}, 0.93$ to 1.35 ) in the matched SAI cohorts (Table 2). Kaplan-Meier estimates revealed no differences in 30-day all-cause in-hospital mortality neither among patients with PAI (Fig. 2A), nor among patients with SAI (Fig. 2B) when compared with matched controls, respectively.

\section{ICU admission and intubation}

Patients with PAI had 1.9-fold increased odds of being admitted to ICU when compared with matched controls (OR 1.85, 95\% CI, 1.27 to $2.72 ; P=0.002$ ). This observation was analog among patients with SAI (OR $1.54 ; 95 \%$ CI 1.35 to $1.75 ; P<0.001)$. Length of ICU stay was not different between patients with PAI and matched controls, however, slightly increased by 1.7 days in patients with SAI compared to matched controls (Table 2). Among patients admitted to ICU, there was no significant difference in intubation rates in the PAI cohort compared to controls. However, for patients with SAI odds for intubation were 1.5-fold increased when compared to propensity score-matched controls (OR 1.54, 95\% CI, 1.28 to $1.87 ; P<0.001)$, with as well prolonged length of intubation (Table 2).

\section{Length of hospital stay and hospital readmission}

Compared with matched controls, mean LOS was prolonged by 1 day in PAI patients (95\% CI, 0.06 to $1.93 ; P=0.037)$ and by 3.3 days in SAI patients $(95 \% \mathrm{CI}$, 2.82 to $3.71 ; \quad P<0.001$ ) (Table 2 ). Accordingly, 
Table 1 Baseline characteristics.

\begin{tabular}{|c|c|c|c|c|c|c|}
\hline & \multicolumn{3}{|c|}{ Primary adrenal insufficiency vs matched controls } & \multicolumn{3}{|c|}{ Secondary adrenal insufficiency vs matched controls } \\
\hline & $\begin{array}{c}\text { Primary adrenal } \\
\text { insufficiency } \\
(n=594) \\
\end{array}$ & Control $(n=594)$ & $\begin{array}{l}\text { Standardized } \\
\text { difference, } \%\end{array}$ & $\begin{array}{c}\text { Secondary adrenal } \\
\text { insufficiency } \\
(n=4880) \\
\end{array}$ & Control $(n=4880)$ & $\begin{array}{l}\text { Standardized } \\
\text { difference, \% }\end{array}$ \\
\hline \multicolumn{7}{|l|}{ Sociodemographics } \\
\hline Age, mean (S.D.) & $65.1(19.0)$ & $64.2(20.2)$ & 4.4 & $68.1(14.9)$ & $68.9(16.2)$ & 5.0 \\
\hline Female gender, $n(\%)$ & $317(53.4)$ & $333(56.1)$ & 5.4 & $2447(50.1 \%)$ & $2519(51.6 \%)$ & 3.0 \\
\hline Swiss residents, $n(\%)$ & $489(82.3)$ & $486(81.8)$ & 1.5 & $4133(84.7 \%)$ & $4164(85.3 \%)$ & 2.1 \\
\hline \multicolumn{7}{|l|}{$\begin{array}{l}\text { Hospital teaching } \\
\text { level, } n(\%)\end{array}$} \\
\hline Tertiary care hospital & $407(68.5)$ & $424(71.4)$ & 6.2 & $3644(74.7 \%)$ & $3634(74.5 \%)$ & 0.5 \\
\hline \multicolumn{7}{|c|}{ Main reasons for hospital admission, $n(\%)$} \\
\hline Endocrine & $154(25.9)$ & $149(25.1)$ & 1.9 & $550(11.3)$ & $505(10.4)$ & 3.0 \\
\hline Infections & $86(14.5)$ & $88(14.8)$ & 0.9 & 559 (11.5) & $537(11.0)$ & 1.4 \\
\hline Cardiovascular & 79 (13.3) & $70(11.8)$ & 4.6 & $548(11.2)$ & $502(10.3)$ & 3.0 \\
\hline Cancer & 49 (8.2) & $50(8.4)$ & 0.6 & 709 (14.5) & 759 (15.6) & 2.9 \\
\hline Pulmonary & $76(12.8)$ & $96(16.2)$ & 9.6 & $1044(21.4)$ & $1113(22.8)$ & 3.4 \\
\hline \multicolumn{7}{|l|}{ Comorbidities, $n(\%)$} \\
\hline Diabetes mellitus & $121(20.4)$ & $121(20.4)$ & 0.0 & $1147(23.5)$ & 1149 (23.5) & 0.1 \\
\hline Hypertension & $182(30.6)$ & $178(30.0)$ & 1.5 & $2290(46.9)$ & $2246(46.0)$ & 1.8 \\
\hline CAD & $74(12.5)$ & $61(10.3)$ & 6.9 & $820(16.8)$ & $721(14.8)$ & 5.6 \\
\hline $\begin{array}{l}\text { Cerebrovascular } \\
\text { disease }\end{array}$ & $22(3.7)$ & $19(3.2)$ & 2.8 & $180(3.7)$ & $164(3.4)$ & 1.8 \\
\hline Cancer & $71(12.0)$ & 73 (12.3) & 1.0 & $1076(22.0)$ & $1091(22.4)$ & 0.7 \\
\hline Renal insufficiency & $150(25.3)$ & $150(25.3)$ & 0.0 & $1511(31.0)$ & $1518(31.1)$ & 0.3 \\
\hline COPD & $72(12.1)$ & 76 (12.8) & 2.0 & $1312(26.9)$ & $1291(26.5)$ & 1.0 \\
\hline $\begin{array}{l}\text { Charlson comorbidity } \\
\text { index, mean (s.D.) }\end{array}$ & $1.6(2.3)$ & $1.6(2.3)$ & 1.1 & $2.4(2.7)$ & $2.5(2.7)$ & 0.9 \\
\hline
\end{tabular}

CAD, Ccoronary artery disease; COPD, Cchronic obstructive pulmonary disease.

Kaplan-Meier estimates showed a longer time to discharge in both adrenal insufficiency groups compared to their corresponding matched cohorts (Fig. 3A and B).

In PAI patients there was no significant difference in 30-day all-cause hospital readmission in comparison with matched controls. However, $14.1 \%$ of SAI cases versus $12.1 \%$ of matched controls were readmitted to hospital within 30 days resulting in an odds ratio of 1.20 (95\% CI, 1.07 to 1.35 ; $P=0.002$ ) (Table 2 ). Corresponding KaplanMeier estimates are shown in Fig. 4A and B. At 1 year, there was no difference in hospital readmission rates among PAI patients when compared to matched controls, while half of the cases with SAI were re-admitted to hospital, compared with 40.7\% among matched controls (OR 1.45, 95\% CI 1.34 to $1.58 ; P<0.001$ ) (Fig. 4C, D and Table 2).

In hospitalized cases with PAI, 30-day readmissions were predominantly due to nonendocrine causes $(80.8 \%)$ and in $19.2 \%$ due to endocrine causes. Compared with matched controls, patients with PAI had a numerically higher proportion of readmissions for endocrine reasons (10 (19.2\%) vs $4(8.3 \%)$ ) and higher proportion of musculoskeletal (4 (7.7\%) vs $2(4.2 \%))$, and dermatologic (3 $(5.8 \%)$ vs 0$)$ causes of readmissions; however, none of these differences met statistical significance (Fig. 5A and Supplementary Table 1).

Of the 690 30-day readmissions in cases with SAI, 663 (96.1\%) were due to nonendocrine causes and 27 (3.9\%) were due to endocrine causes. Among nonendocrine causes of readmission, respiratory (109 (15.8\%) vs $83(14.1 \%))$, infectious (48 (7.0\%) vs $28(4.8 \%))$, and musculoskeletal (41 (5.0\%) vs $14(2.4 \%))$ readmissions were numerically more prevalent in patients with SAI compared to matched controls, however, merely the latter meeting statistical significance (Fig. 5B and Supplementary Table 1). The most common cause, in general, was oncologic and hematologic, but significantly more prevalent among matched controls (202 (29.3\%) vs 207 (35.2\%), P=0.02) (Fig. 5B).

\section{Discussion}

This population-based cohort study assessing the healthcare burden of more than 5000 propensity score-matched hospitalized cases with adrenal insufficiency has two key findings: First, adrenal insufficiency carries a clinically 
Table 2 Primary and secondary outcomes.

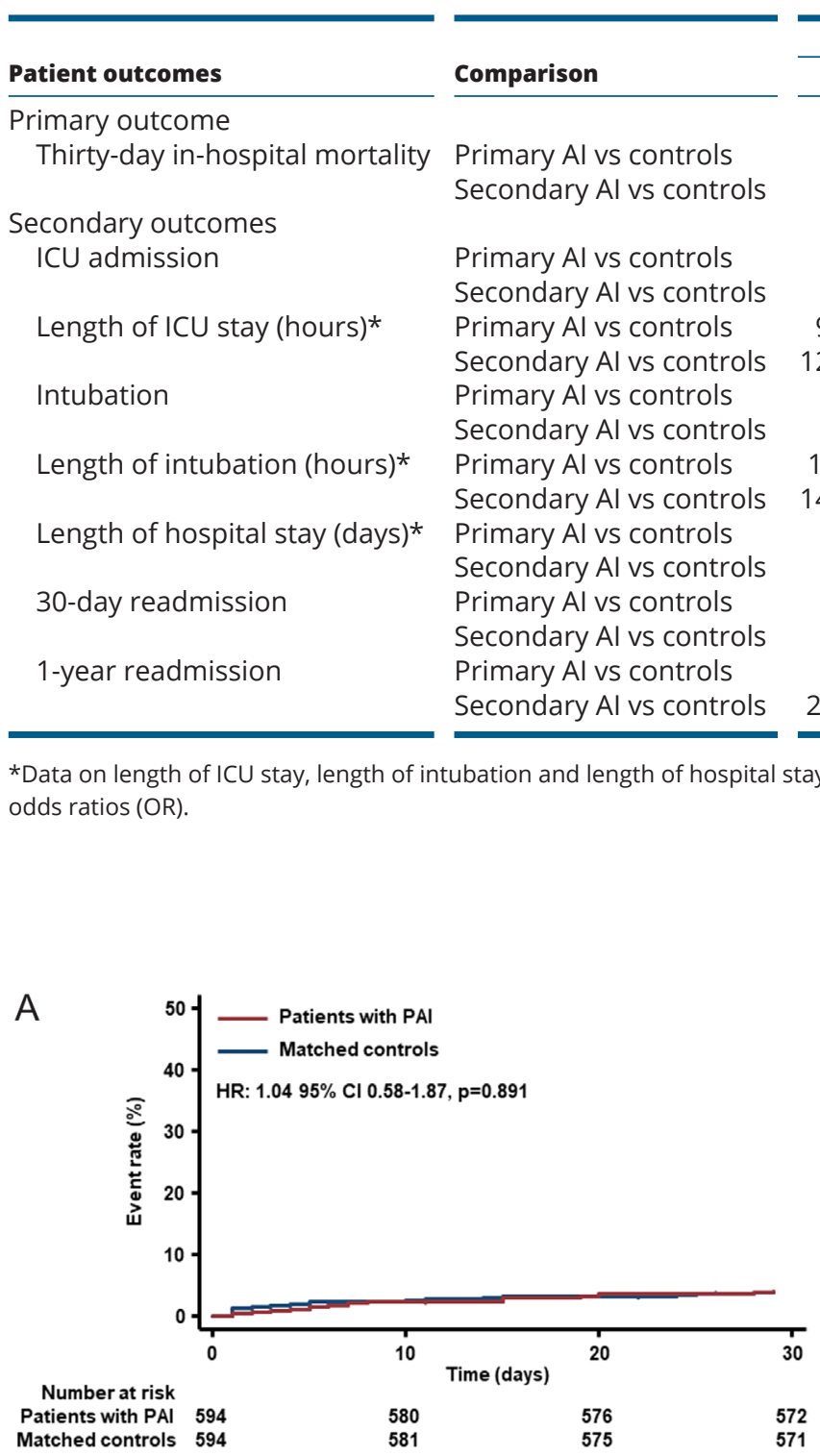

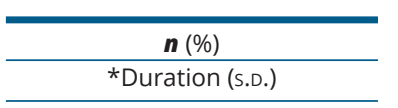

\begin{tabular}{|c|c|}
\hline OR $(95 \% \mathrm{Cl})$ & \\
\hline *Regression coefficient (95\% Cl) & $P$ value \\
\hline 1.05 (0.58 to 1.90$)$ & 0.879 \\
\hline $1.12(0.93$ to 1.35$)$ & 0.250 \\
\hline 1.85 (1.27 to 2.72$)$ & 0.002 \\
\hline 1.54 (1.35 to 1.75$)$ & $<0.001$ \\
\hline $28.9(-23.4$ to 81.2$)$ & 0.277 \\
\hline 40.7 (16.0 to 65.4$)$ & 0.001 \\
\hline 1.55 (0.83 to 2.89$)$ & 0.165 \\
\hline 1.54 (1.28 to 1.87$)$ & $<0.001$ \\
\hline $93.3(-12.6$ to 199.3$)$ & 0.083 \\
\hline 45.1 (3.82 to 86.39$)$ & 0.032 \\
\hline 0.99 (0.06 to 1.93$)$ & 0.037 \\
\hline 3.27 (2.82 to 3.71$)$ & $<0.001$ \\
\hline $1.09(0.72$ to 1.64$)$ & 0.676 \\
\hline $1.20(1.07$ to 1.35$)$ & 0.002 \\
\hline $1.15(0.91$ to 1.45$)$ & 0.253 \\
\hline 1.45 (1.34 to 1.58$)$ & $<0.001$ \\
\hline
\end{tabular}

23 vs 22 (3.9 vs 3.7)

240 vs 216 (4.9 vs 4.4)

80 vs 46 (13.5 vs 7.7)

647 vs 441 (13.3 vs 9.0)

94.1 (166.6) vs 65.2 (86.6)

129.6 (238.4) vs 88.9 (137.9)

26 vs 17 (4.4 vs 2.9)

283 vs 187 (5.8 vs 3.8)

137.9 (206.0) vs $44.6(78.4)$

$140.0(262.9)$ vs $94.9(142.1)$

$8.9(9.1)$ vs $7.9(7.1)$

12.1 (12.6) vs 8.8 (9.4)

52 vs 48 ( 8.8 vs 8.1$)$

690 vs 588 (14.1 vs 12.1)

228 vs 209 (38.4 vs 35.2)

2439 vs 1987 (50.0 vs 40.7)

*Data on length of ICU stay, length of intubation and length of hospital stay are presented as regression coefficients. All other outcomes are presented as odds ratios (OR).

Matched controls 594

A

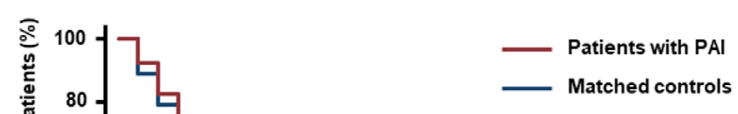

HR: $0.9295 \% \mathrm{Cl}$ 0.82-1.03, $\mathrm{p}=0.141$

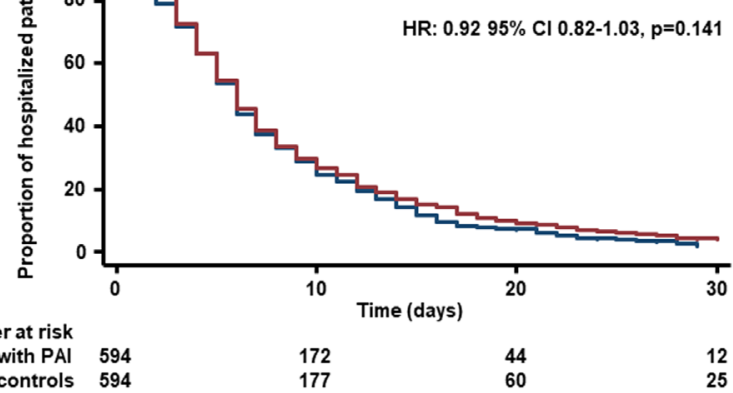

B

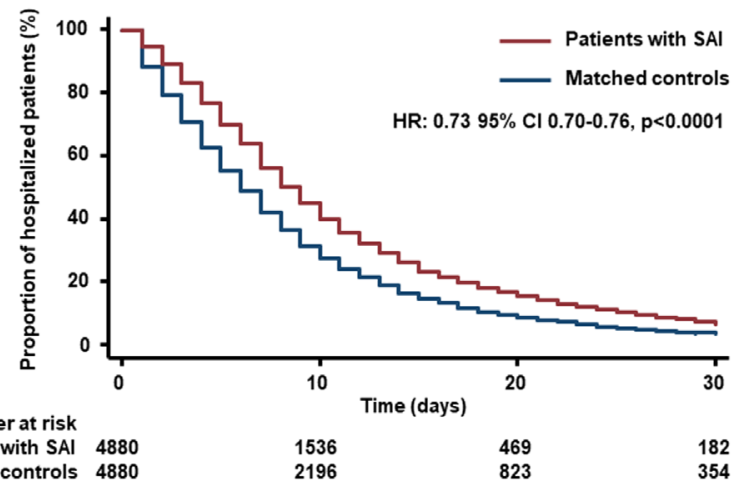

Figure 3

Time to discharge: (A) PAl cohort vs matched controls and (B) SAl cohort vs matched controls. 


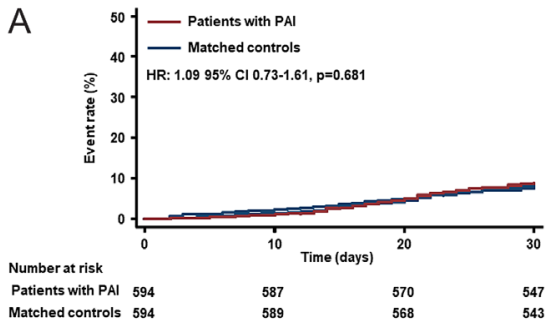
Matched controls 594

C

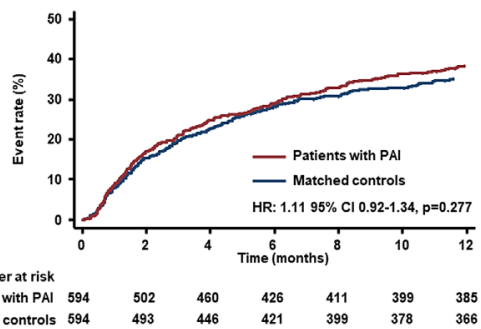

B

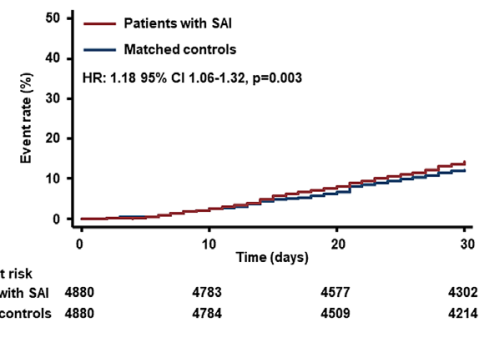

D

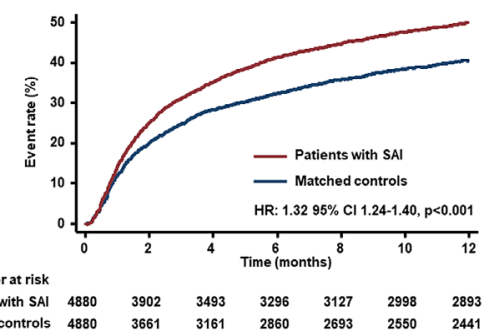

\section{Figure 4}

All-cause readmission rates: (A) 30-dayand $(C)$ 1-year readmission rates in PAI cohort vs matched controls, and (B) 30-day and (D) 1-year readmission rates in SAl cohort vs matched controls.

relevant health-care burden, as mirrored by increased ICU admission and intubation rates, prolonged LOS, and higher hospital readmission rates, in particular among cases with SAI. Second, it is nonetheless reassuring that unlike data on long-term survival in the outpatient setting (12), there was no increased in-hospital mortality in our study. Whether our findings are due to higher demand of health-care resources as mirrored by prolonged hospital stay and increased readmission rates or due to higher vulnerability of patients with adrenal insufficiency remains debatable.

In line with our findings, outpatients with adrenal insufficiency are at increased risk of hospital admission and reduced quality-of-life when compared with the general population $(10,18,19)$. Due to long-term excess of glucocorticoid exposure, patients with adrenal insufficiency are at increased risk of developing comorbid conditions such as obesity, diabetes mellitus, hypertension, and depression (10). These comorbidities strongly contribute to an increased cardiovascular risk profile $(20,21)$. Against this background we used a propensity score matching taking all relevant and documented comorbidities into account achieving well-balanced patient characteristics when compared to matched controls, in order to minimize possible confounding on the investigated outcomes.

Worse outcomes in patients with adrenal insufficiency may at least in part be explained by an inappropriate glucocorticoid replacement therapy in the context of stress and acute illnesses. In fact, previous studies have revealed that doses of glucocorticoid replacement were often too high and should be reduced in around half of the patients (22). Besides, glucocorticoid hormone supplementation in the acute care setting is generally complicated by the need to adjust glucocorticoid dosage during hospitalization which may as well explain a prolonged hospital stay and higher demand of health-care resources (23).

In addition, there is increasing evidence that patients with adrenal insufficiency on glucocorticoid replacement therapy often exhibit a pro-inflammatory state and weakened immune defense due to over-supply, which has recently been shown to be less pronounced with modified-release preparations when compared with multiple daily dosing of short-acting formulations (24). Consequently, patients with adrenal insufficiency are known to suffer from more frequent and severe infections (14), mainly due to an impairment of innate and adaptive immunity (25). On the other hand, under-supply can lead to adrenal crisis and reduced quality of life $(9,26)$. Hence, observed differences in ICU admission rates and LOS may therefore be due to an augmented susceptibility to hemodynamic instability in the context of acute medical conditions, such as infections, trauma, and major psychological distress which are known predisposing factors for adrenal crisis $(9,27,28)$. In agreement with the literature, we found a numerically higher amount of infections and cardiovascular reasons as main cause for hospital readmissions in SAI patients compared to matched controls, however, not meeting statistical significance, respectively. Interestingly, the main causes for 30-day hospital readmission did not relevantly differ from matched controls, neither in PAI nor in SAI patients. This further supports the robustness of the matched cohorts and the validity of the model considering index admission causes which have been described among the main determinants of readmission causes (29).

It is worth mentioning that patients with tertiary adrenal insufficiency were pooled into the SAI cohort 
A

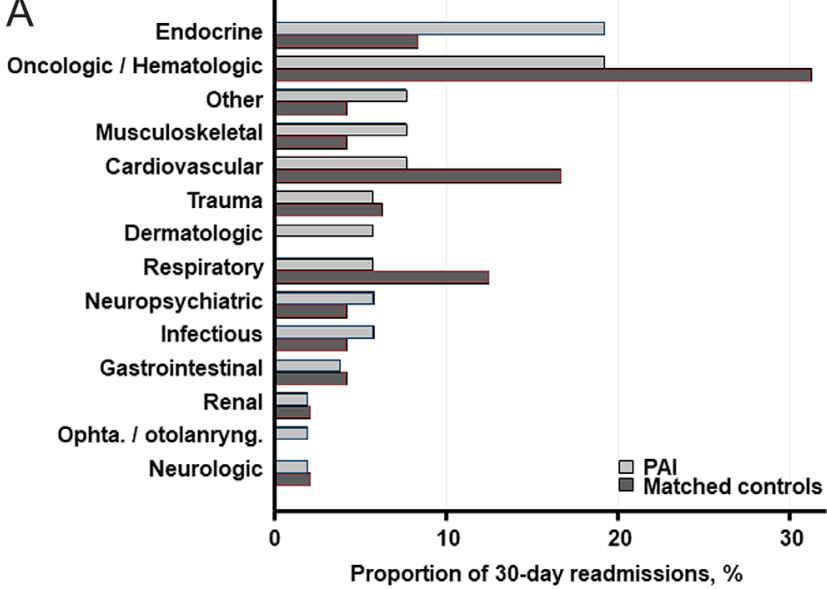

B

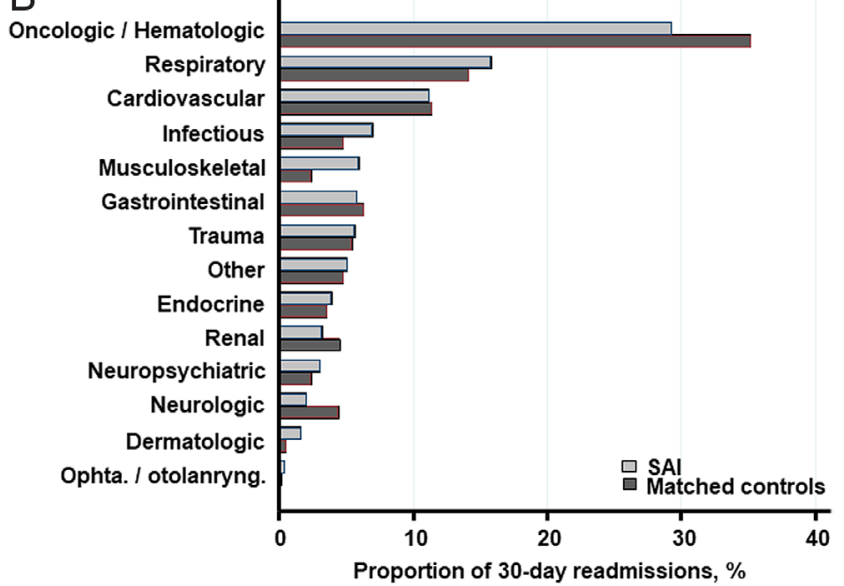

Figure 5

Causes of 30-day readmissions in patients with PAI (A) and SAI (B) versus their matched controls.

which may have pertinently influenced the results since these patients have high rates of oncologic, respiratory, and cardiovascular diagnoses. Since many patients in the SAI cohort had iatrogenic adrenal insufficiency from high-dose glucocorticoid treatment, there was in fact a higher rate of COPD and cancer among SAI patients. However, due to common ICD coding of secondary and tertiary adrenal insufficiency in the SwissDRG dataset, subgroup analyses investigating differences in outcomes between these patient cohorts were not feasible.

Nevertheless, challenging our findings one could hypothesize that the higher ICU admission rates and prolonged LOS do not reflect the burden of disease per se but rather a higher awareness of physicians toward the vulnerability of patients with adrenal insufficiency. However, current literature does not provide sufficient evidence for this hypothesis (23).
Ourstudy has somelimitations. First, the administrative nature of the database and the cross-sectional design carry the risk for unmeasured confounding, under-reporting of secondary diagnoses, and varying accuracy of coding between hospitals. Furthermore, information bias in coding of patients with underlying chronic conditions cannot be excluded in discharge claims data. Second, lack of data on etiology and duration of SAI as well as on glucocorticoid supplementation did not allow for cluster analyses, respectively. Importantly, there may have been patients with pituitary disorders and dysfunction of other pituitary axes which could have had an effect modification on the assessed outcomes. Third, propensity score matching could not account for the severity of the acute medical condition leading to hospitalization. Finally, our analysis was limited to hospitalized patients with acute medical conditions. Episodes of adrenal insufficiency diagnosed and treated in emergency departments but not hospitalized were not available and therefore missing in our study. Thus, the findings may not be generalizable to patients admitted to surgical departments, or other specialties, and as well not to outpatient care of patients with adrenal insufficiency.

However, the following strengths are noteworthy: we used registry data spanning nationwide hospital care with a large sample size, high representativity, and a long study period. Thus, with the application of a weighted analysis, our study reflects highly accurate estimates at the national level. As these national estimates have not been presented before, it would be useful to replicate this study using different and more sophisticated resources.

In conclusion, there is a relevant health-care burden among adult patients with adrenal insufficiency hospitalized for acute medical conditions. Based on these findings increased efforts are warranted to tackle these short-comings of patient-oriented outcomes in this vulnerable patient population.

\section{Supplementary data}

This is linked to the online version of the paper at https://doi.org/10.1530/ EJE-19-0469.

Declaration of interest

The authors declare that there is no conflict of interest that could be perceived as prejudicing the impartiality of this study.

\section{Funding}

This study was supported in part by the Swiss National Science Foundation (SNSF, National Research Program (NRP 74), 407440_167376). 


\section{Author contribution statement}

F E, A W, M C C, and A K designed the study and wrote the manuscript. $\mathrm{A} \mathrm{K}$ had access to all the data. F E and A K analyzed the data and were responsible for the decision to submit the manuscript. All authors provided comments on drafts and approved the final report.

\section{Role of the funding source}

The funding sources had no role in study design, data collection, data analysis, data interpretation, or writing of the report.

\section{References}

1 Charmandari E, Nicolaides NC \& Chrousos GP. Adrenal insufficiency. Lancet 2014383 2152-2167. (https://doi.org/10.1016/S01406736(13)61684-0)

2 Bornstein SR, Allolio B, Arlt W, Barthel A, Don-Wauchope A, Hammer GD, Husebye ES, Merke DP, Murad MH, Stratakis CA et al. Diagnosis and treatment of primary adrenal insufficiency: an Endocrine Society clinical practice guideline. Journal of Clinical Endocrinology and Metabolism 2016101 364-389. (https://doi. org/10.1210/jc.2015-1710)

3 Gordijn MS, Gemke RJ, van Dalen EC, Rotteveel J \& Kaspers GJ. Hypothalamic-pituitary-adrenal (HPA) axis suppression after treatment with glucocorticoid therapy for childhood acute lymphoblastic leukaemia. Cochrane Database of Systematic Reviews 2012 CD008727. (https://doi.org/10.1002/14651858.CD008727. pub2)

4 Woods CP, Argese N, Chapman M, Boot C, Webster R, Dabhi V, Grossman AB, Toogood AA, Arlt W, Stewart PM et al. Adrenal suppression in patients taking inhaled glucocorticoids is highly prevalent and management can be guided by morning cortisol. European Journal of Endocrinology 2015173 633-642. (https://doi. org/10.1530/EJE-15-0608)

5 Bornstein SR. Predisposing factors for adrenal insufficiency. New England Journal of Medicine 2009360 2328-2339. (https://doi. org/10.1056/NEJMra0804635)

6 Dunlop D. Eighty-six cases of Addison's disease. British Medical Journal 19632 887-891. (https://doi.org/10.1136/bmj.2.5362.887)

7 Andela CD, Staufenbiel SM, Joustra SD, Pereira AM, van Rossum EFC $\&$ Biermasz NR. Quality of life in patients with adrenal insufficiency correlates stronger with hydrocortisone dosage, than with long-term systemic cortisol levels. Psychoneuroendocrinology 201672 80-86. (https://doi.org/10.1016/j.psyneuen.2016.06.015)

8 Grossman A, Johannsson G, Quinkler M \& Zelissen P. Therapy of endocrine disease: perspectives on the management of adrenal insufficiency: clinical insights from across Europe. European Journal of Endocrinology 2013169 R165-R175. (https://doi.org/10.1530/EJE-130450)

9 Rushworth RL, Torpy DJ \& Falhammar H. Adrenal crisis. New England Journal of Medicine 2019381 852-861. (https://doi.org/10.1056/ NEJMra1807486)

10 Stewart PM, Biller BMK, Marelli C, Gunnarsson C, Ryan MP \& Johannsson G. Exploring inpatient hospitalizations and morbidity in patients with adrenal insufficiency. Journal of Clinical Endocrinology and Metabolism 2016101 4843-4850. (https://doi.org/10.1210/ jc. 2016-2221)

11 Tomlinson JW, Holden N, Hills RK, Wheatley K, Clayton RN, Bates AS, Sheppard MC \& Stewart PM. Association between premature mortality and hypopituitarism. West Midlands Prospective Hypopituitary Study Group. Lancet 2001357 425-431. (https://doi. org/10.1016/S0140-6736(00)04006-X)
12 Bergthorsdottir R, Leonsson-Zachrisson M, Odén A \& Johannsson G. Premature mortality in patients with Addison's disease: a populationbased study. Journal of Clinical Endocrinology and Metabolism 200691 4849-4853. (https://doi.org/10.1210/jc.2006-0076)

13 Erichsen MM, Løvås K, Fougner KJ, Svartberg J, Hauge ER, Bollerslev J, Berg JP, Mella B \& Husebye ES. Normal overall mortality rate in Addison's disease, but young patients are at risk of premature death. European Journal of Endocrinology 2009160 233-237. (https:// doi.org/10.1530/EJE-08-0550)

14 Smans LCCJ, Souverein PC, Leufkens HGM, Hoepelman AIM \& Zelissen PMJ. Increased use of antimicrobial agents and hospital admission for infections in patients with primary adrenal insufficiency: a cohort study. European Journal of Endocrinology 2013 168 609-614. (https://doi.org/10.1530/EJE-12-0879)

15 Swiss DRG. Regeln und Definitionen zur Fallabrechnung unter SwissDRG. 2017 Available at: (https://www.swissdrg.org/application/ files/4714/8111/3146/160620_SwissDRG_Falldefinitionen_v5.pdf); Accessed on 1 September 2019.

16 Elm E von, Altman DG, Egger M, Pocock SJ, Gøtzsche PC, Vandenbroucke JP \& STROBE Initiative. The Strengthening the Reporting of Observational Studies in Epidemiology (STROBE) Statement: guidelines for reporting observational studies. International Journal of Surgery 201412 1495-1499. (https://doi. org/10.1016/j.ijsu.2014.07.013)

17 Austin PC. An introduction to propensity score methods for reducing the effects of confounding in observational studies. Multivariate Behavioral Research 201146 399-424. (https://doi.org/10.1080/00273 171.2011.568786)

18 Bleicken B, Hahner S, Loeffler M, Ventz M, Decker O, Allolio B \& Quinkler M. Influence of hydrocortisone dosage scheme on healthrelated quality of life in patients with adrenal insufficiency. Clinical Endocrinology 201072 297-304. (https://doi.org/10.1111/j.13652265.2009.03596.x)

19 Bleicken B, Hahner S, Loeffler M, Ventz M, Allolio B \& Quinkler M. Impaired subjective health status in chronic adrenal insufficiency: impact of different glucocorticoid replacement regimens. European Journal of Endocrinology 2008159 811-817. (https://doi.org/10.1530/ EJE-08-0578)

20 Filipsson H, Monson JP, Koltowska-Häggström M, Mattsson A \& Johannsson G. The impact of glucocorticoid replacement regimens on metabolic outcome and comorbidity in hypopituitary patients. Journal of Clinical Endocrinology and Metabolism 200691 3954-3961. (https://doi.org/10.1210/jc.2006-0524)

21 Rahvar AH, Haas CS, Danneberg S \& Harbeck B. Increased cardiovascular risk in patients with adrenal insufficiency: a short review. BioMed Research International 20172017 3691913. (https:// doi.org/10.1155/2017/3691913)

22 Debono M, Ross RJ \& Newell-Price J. Inadequacies of glucocorticoid replacement and improvements by physiological circadian therapy. European Journal of Endocrinology 2009160 719-729. (https://doi. org/10.1530/EJE-08-0874)

23 Bancos I, Hahner S, Tomlinson J \& Arlt W. Diagnosis and management of adrenal insufficiency. Lancet: Diabetes and Endocrinology 20153 216-226. (https://doi.org/10.1016/S22138587(14)70142-1)

24 Isidori AM, Venneri MA, Graziadio C, Simeoli C, Fiore D, Hasenmajer V, Sbardella E, Gianfrilli D, Pozza C, Pasqualetti P et al. Effect of once-daily, modified-release hydrocortisone versus standard glucocorticoid therapy on metabolism and innate immunity in patients with adrenal insufficiency (DREAM): a single-blind, randomised controlled trial. Lancet: Diabetes and Endocrinology 20186 173-185. (https://doi.org/10.1016/S2213-8587(17)30398-4)

25 Bancos I, Hazeldine J, Chortis V, Hampson P, Taylor AE, Lord JM \& Arlt W. Primary adrenal insufficiency is associated with impaired natural killer cell function: a potential link to increased mortality. 
European Journal of Endocrinology 2017176 471-480. (https://doi. org/10.1530/EJE-16-0969)

26 Øksnes M, Bensing S, Hulting AL, Kämpe O, Hackemann A, Meyer G, Badenhoop K, Betterle C, Parolo A, Giordano R et al. Quality of life in European patients with Addison's disease: validity of the diseasespecific questionnaire AddiQoL. Journal of Clinical Endocrinology and Metabolism 201297 568-576. (https://doi.org/10.1210/jc.2011-1901)

27 Hahner S, Loeffler M, Bleicken B, Drechsler C, Milovanovic D, Fassnacht M, Ventz M, Quinkler M \& Allolio B. Epidemiology of adrenal crisis in chronic adrenal insufficiency: the need for new prevention strategies. European Journal of Endocrinology 2010162 597-602. (https://doi.org/10.1530/EJE-09-0884)

28 White K \& Arlt W. Adrenal crisis in treated Addison's disease: a predictable but under-managed event. European Journal of Endocrinology 2010162 115-120. (https://doi.org/10.1530/EJE-09-0559)

29 Auerbach AD, Kripalani S, Vasilevskis EE, Sehgal N, Lindenauer PK, Metlay JP, Fletcher G, Ruhnke GW, Flanders SA, Kim C et al. Preventability and causes of readmissions in a national cohort of general medicine patients. JAMA Internal Medicine 2016176 484-493. (https://doi.org/10.1001/jamainternmed.2015.7863)

Received 23 June 2019

Revised version received 20 September 2019

Accepted 3 October 2019 